\title{
A RELAÇÃO ENTRE TRABALHO E EDUCAÇÃO E AS IMPLICAÇÕES NO ÂMBITO DAS ESCOLAS PÚBLICAS DE FORTALEZA/CE
}

\author{
THE RELATIONSHIP BETWEEN WORK AND EDUCATION AND THE IMPLICA- \\ TIONS IN THE PUBLIC SCHOOLS OF FORTALEZA/CE
}

\section{LA RELACIÓN ENTRE EL TRABAJO Y LA EDUCACIÓN Y LAS CONSECUEN- CIAS EN EL CONTEXTO DE LAS ESCUELAS PÚBLICAS DE FORTALEZA / CE}

\author{
Clarice Zientarski \\ Professora Doutora do Departamento de Fundamentos da Educação da \\ Universidade Federal do Ceará. \\ claricezientarski@yahoo.com.br
}

\begin{abstract}
RESUMO: O estudo trata sobre as relações que se estabelecem entre o Trabalho e a Educação no contexto da sociedade dominada pelo capital, e as implicações destas relações no âmbito das instituições educacionais. Tem como fonte empírica dez (10) escolas da rede pública estadual do Ceará, localizadas no município de Fortaleza, que assumem o compromisso de atender às determinações do Instituto Unibanco em nome da gestão eficiente, participativa e com foco nos resultados positivos, por meio do Programa Jovem do Futuro. Trata-se de uma pesquisa com abordagem qualitativa, que utilizou como instrumentos, documentos e entrevistas semiestruturadas com professores gestores das escolas e estudantes. Concluiu que as parcerias com os institutos privados e outros órgãos externos às escolas reforçam e consolidam a relação entre trabalho e educação, no que diz respeito à lógica do mercado e da meritocracia, ou seja, do trabalho estranhado.
\end{abstract}

PALAVRAS-CHAVE: Trabalho e educação. Parceria público/privado. Políticas educacionais.

ABSTRACT: The study deals with the relationships established between Labor and Education in the context of society dominated by capital, and the implications of these relationships within the educational institutions. The work has like empirical source ten (10) schools in the public state of Ceará, located in Fortaleza, who commit to meeting certain requirements of Instituto Unibanco in the name of efficient management, participatory and focused on positive result through the Programa Jovem do Futuro. This is a research with qualitative approach, which used as instruments, documents and semi-structured interviews with managers school teachers and students. Concluded that partnerships of private institutes and of other external agencies with schools reinforce and consolidate the relationship between work and education, with regard to the logico of the market and meritocracy, that is, the estranged work.

KEYWORDS: Work and Education. Public / private partnership. Educational policies.

RESUMEN: El estudio se ocupa de las relaciones que se establecen entre el Trabajo y la Educación en el contexto de la sociedad dominada por el capital, y las implicaciones de estas relaciones dentro de las instituciones educativas. Su fuente empírica son diez (10) escuelas públicas de Ceará, que se encuentra en Fortaleza, que se comprometen a cumplir con ciertos requisitos del Instituto Unibanco en el nombre de eficiente, participativa y centrada en los resultados positivos a través del Programa Joven del Futuro. Se trata de una investigación con enfoque cualitativo, que utiliza como instrumentos, documentos y entrevistas semi estructuradas con profesores de las escuelas, los gerentes y los estudiantes. Concluyeron que las asociaciones con los institutos privados y otros organismos externos a las escuelas refuerzan y consolidan la relación entre el trabajo y la educación, con respecto a la lógica del mercado y la meritocracia, es decir, el trabajo enajenado.

PALABRAS CLAVE: Trabajo y educación. Asociación público/privado. Políticas educación.

$\overline{\text { Artigo recebido em janeiro de } 2015}$

Aprovado em março de 2015

Cad. Pes., São Luís, v. 22, n. 1, jan./abr. 2015 


\section{A RELAÇÃO ENTRE TRABALHO E EDUCAÇÃO | Clarice Zientarski}

\section{1 | INTRODUÇÃO}

Este estudo trata sobre as relações que se estabelecem entre o Trabalho e a Educação no contexto da sociedade dominada pelo capital, e as implicações destas relações no âmbito das instituições de ensino, tendo como espaço empírico dez (10) escolas da rede pública estadual do Ceará, localizadas no município de Fortaleza. Para a discussão sobre a temática, parte do pressuposto de que o trabalho é fundante na essência humana. Ser fundante, não indica algo que antecede, ou que vem antes, pois, "somente o trabalho tem, como sua essência ontológica, um claro caráter intermediário: ele é, essencialmente, uma interação entre homem (sociedade) e natureza" (LUKÁCS, 1978, p. 4). Ontologicamente, o trabalho é uma atividade inerente ao homem e, como assegura Marx (2011) o trabalho é atividade vital do homem, pois, este expressa seu verdadeiro caráter genérico enquanto trabalhador, na produção e reprodução de suas condições materiais.

Nessa perspectiva, se entende com Marx que o trabalho é definidor da natureza humana, fonte de sobrevivência, mas, também de realização e humanização. $O$ trabalho se constitui ainda como categoria social, pois, não pode ser compreendido fora desta dimensão social e historicamente determinado. Diante dessa afirmação, se pode constatar que o trabalho tem uma importância tão grande, que uma vez compreendida a sua historicidade material e dialética, permite alcançar uma definição de homem como sendo aquele ente que, para ser, necessita produzir os seus próprios meios de subsistência. Assim, o trabalho humano é que valoriza os objetos, mo qual se entende que as coisas têm valor por ter trabalho humano incorporado; entretanto, o trabalho e as contradições que envolvem as relações de produção são tão significativos que a sua reorganização provocou um conjunto de profundas transformações sociais, econômicas, políticas não apenas no Brasil, mas, na grande maioria dos países capitalistas. Estas mudanças associadas ao processo de reestruturação produtiva em nível internacional se caracterizam pela difusão de inovações tecnológicas e organizacionais, nas mais diversas cadeias produtivas e pela reorganização dos mercados. No centro dessas transformações verifica-se um intenso processo de reorganização do trabalho e de elevação da produtividade, afetando o volume e a estrutura do emprego, o perfil e a hierarquização das qualificações e os padrões de gestão da força de trabalho.

A compreensão da dinâmica e da natureza desse processo de mudança não é tarefa fácil, mas é fundamental para a formulação de estratégias de desenvolvimento econômico e social mais humano e menos excludente. O mundo do trabalho resultante da mundialização, segundo Chesnais (1996), permite introduzir a ideia de que se a economia se mundializou e que seria importante construir instituições políticas mundiais capazes de dominar o seu movimento. Nessa lógica, a instituição educacional reforça esse processo, refletindo e impondo novas perspectivas para a formação e qualificação da mão de obra, em atendimento ao que é estabelecido pelo mercado. Tal situação instala-se a partir da crise estrutural do capital e apresenta-se como resposta à própria crise quando iniciou-se um processo de reorganização do capital cujos contornos "mais evidentes foram o advento do Neoliberalismo, com a privatização do Estado, a desregulamentação dos direitos do trabalho e a desmontagem do setor produtivo estatal [...]" (ANTUNES, 1999, p. 31). Considera-se que o Estado gasta mais do que pode e, por esta razão, sob a ótica neoliberal, acaba limitando os projetos de livre andamento do mercado, então, precisa ser afastado e limitada a sua ação em relação às políticas sociais. Nesse sentido, a partir do momento que o Estado não atende, não dá conta do seu papel, é necessário que remeta às políticas sociais à sociedade civil e/ou às instituições que a representam.

É o que pode ser constatado em escolas da rede pública estadual do Ceará, que neste estudo são objeto de investigação, por assumirem projetos e programas definidos a partir de acordos en- 


\section{A RELAÇÃO ENTRE TRABALHO E EDUCAÇÃO | Clarice Zientarski}

tre a secretaria de educação, entenda-se governo do Estado do Ceará, e iniciativa privada, como é o caso do Instituto Unibanco. A parceria público/privado, assim como se verifica no Ceará, cada vez mais tem influenciado a política educacional e podem ser vistas várias parcerias no Brasil entre instituições do terceiro setor e os sistemas públicos de ensino. Fernandes (1994) argumenta que o terceiro setor é caracterizado como o Público não Estatal e pressupõe a existência do primeiro e segundo, ou seja, Estado e Mercado. O conceito designa "um conjunto de iniciativas particulares com um sentido público" (FERNANDES, 1994, p. 127). Como asseguram Peroni, Oliveira e Fernandes (2009), o chamado terceiro setor é composto por organizações não-governamentais (ONGs), instituições filantrópicas e comunitárias e outras associações similares. Ainda, as autoras salientam que estes organismos, criados com o objetivo de prover serviços sociais na área de saúde, educação, proteção contra o crime, transporte público, enfim, de alívio à pobreza, têm em comum o fato de serem não-lucrativos e fazerem parte da sociedade civil.

As dez escolas públicas estaduais de Educação Básica em estudo, localizam-se no município de Fortaleza (três no centro e sete em bairros próximos) e apresentam em seus projetos políticos pedagógicos a defesa da autonomia financeira e pedagógica, conforme estabelecem a Constituição Federal de 1988 e a Lei de Diretrizes e Bases (LDB) no 9.394/96. Atendem, por sua vez, ao efeito preconizado pela cultura gerencial da: flexibilidade, autonomia e excelência, disseminadas pelo capital dominante; assumem o compromisso de atender às determinações do Instituto Unibanco em nome da gestão eficiente, participativa e com foco nos resultados positivos. Nesse contexto, a parceria público/privado entre o Ministério da Educação, as Secretarias de Estado e o Instituto Unibanco confirma a intrínseca relação entre trabalho e educação na conjuntura atual. Ao mesmo tempo, corrobora com as definições neoliberais em que:

O papel do Estado para com as políticas sociais é alterado, pois com este diagnósti-
co duas são as prescrições: racionalizar recursos e esvaziar o poder das instituições,
já que instituições democráticas são permeáveis às pressões e demandas da pop-
ulação, além de serem consideradas como improdutivas, pela lógica de mercado.
Assim, a responsabilidade pela execução das políticas sociais deve ser repassa-
da para a sociedade: para os neoliberais, por meio da privatização (mercado), e para
a Terceira Via pelo público não-estatal (sem fins lucrativos). (PERONI, 2006, p. 14).

A partir desse viés teórico, com base na teoria marxiana do trabalho, a pesquisa apresenta-se com abordagem qualitativa, fundamentado em entrevistas com componentes das equipes diretivas, professores regentes de turma e ainda, na análise documental dos projetos políticos pedagógicos (PPP) das escolas. Assim, o estudo investigativo fundamenta-se em um caminho teórico e empírico, pois, "a observação empírica tem de, necessariamente, provar empiricamente e sem nenhum tipo de mistificação ou especulação, em cada caso concreto, a relação existente entre a estrutura social e política e a produção" (MARX; ENGELS, 2007, p. 47). Este, portanto, é o teor do nosso estudo.

\section{2 | A ECONOMIA MUNDIALIZADA E AS RELAÇÕES DE TRABALHO}

O mundo especialmente a partir dos anos 1990, como afirma Oliveira (1990), tem no mercado um novo Deus. O estudioso, entretanto, assegurou já naquele momento, que o neoliberalismo era incapaz de resolver questões como a educação, a saúde e outras que acompanham o homem. $O$ neoliberalismo assim como a globalização são fenômenos reais, embora complexos, com implicações sociopolíticas e econômicas na sociedade. Com a globalização se verificou a subjugação dos Estados Nacionais e sua soberania através de ações e atores transnacionais. Oliveira e 


\section{A RELAÇÃO ENTRE TRABALHO E EDUCAÇÃO | Clarice Zientarski}

Libâneo (1998, p. 606) afirmam que as transformações gerais da sociedade atual apontam a "inevitabilidade de compreender o país no contexto da globalização, da revolução tecnológica e da ideologia do livre mercado". Assim, nesta conjuntura, compreende-se que a globalização é uma tendência internacional do capitalismo que impõe aos países periféricos a economia de mercado global sem restrições, a competição ilimitada e a minimização do Estado na área econômica e social.

Algumas das questões que aparecem em decorrência disso são: a exclusão social, o desemprego e o aumento da miséria. Essa forma de globalização significa a predominância da economia de mercado e do livre mercado, uma situação em que o máximo possível é mercantilizado e privatizado, com o agravante da perda de conquistas sociais. Essas características alimentam o projeto capitalista atual, assimilando as demandas por mais liberdade individual. Neste prisma, foi construído um novo arcabouço econômico para o mundo em que o Estado não exerceria mais a função de distribuição do modelo anterior. Nesta lógica, os serviços públicos devem ser privatizados e os demais recursos, postos a serviço da especulação (ANTUNES, 1999).

As transformações, portanto, pelas quais o mundo passa, sobretudo no final do século $X X$, e no início do século XXI, são alterações que se dão no mundo do trabalho, provocadas pelo capital. Os objetos, os instrumentos, as formas de produção, a organização do trabalho e a qualidade da mão de obra alteraram-se profundamente. As novas tecnologias desempenham enorme papel nestas transformações, ocupando um lugar de destaque na lógica da estrutura socioeconômica. O fechamento de "postos de trabalho", o surgimento de novas profissões, a reorganização do mundo do trabalho fabril/industrial transforma também a vida das pessoas, seus valores, suas formas de percepção e de relacionamento com o outro.

Em termos de estrutura social, conforme alude Andrioli (2002, s/p), intensifica a manutenção da sociedade burguesa, com suas características básicas.

a) trabalho como mercadoria;

b) propriedade privada;

c) controle do excedente econômico;

d) mercado como centro da sociedade;

e) apartheid, exclusão da maioria;

f) educação regulada pela divisão social de classes.

Porém, em termos estruturais, a novidade é que a ordem burguesa está sem alternativa, ou seja, o capitalismo prova sua ineficácia generalizada e a crise apresentada revelam seu caráter endógeno, o capitalismo demonstra explicitamente ser o gerador de seus próprios problemas (ANTUNES, 2004).

O trabalho, portanto, assume as características definidas pelo modelo vigente. Os novos conceitos de produção, que se apresentaram como alternativas ao modelo taylorista/fordista, foram disseminando a ideia de que a reintegração de atividades e o emprego de uma mão de obra mais qualificada eram necessários ao desenvolvimento de um trabalho mais rico e variado. Essas noções tomavam por base o argumento de que a substituição do trabalhador por máquinas não permitiria, por si só, que melhores taxas de produção fossem atingidas (ANTUNES, 2004). A introdução de novos métodos e paradigmas de gestão e organização da produção, o caso do Toyotismo, em lugar de proceder através da destruição dos saberes operários complexos e da decomposição em gestos elementares, vai avançar pela desespecialização dos profissionais para transformá-los não em operários parcelares, mas em plurioperadores, em profissionais polivalentes, em "trabalhadores multifuncionais", conforme salienta Coriat (1994, p. 53): 


\title{
A RELAÇÃO ENTRE TRABALHO E EDUCAÇÃO | Clarice Zientarski
}

\begin{abstract}
Este movimento de desespecialização dos operários profissionais e qualificados, para transformá-los em trabalhadores multifuncionais, é de fato um movimento de racionalização do trabalho no sentido clássico do termo. Trata-se aqui, também como na via taylorista norte-americana, de atacar o saber complexo do exercício dos operários qualificados, a fim de atingir o objetivo de diminuir os seus poderes sobre a produção e de aumentar a intensidade do trabalho.
\end{abstract}

Nesse caso, em última instância, o que se verifica é que o objetivo central continua sendo o de aumentar a intensidade do trabalho e, portanto, da extração de valor. Associado a esse processo é introduzida uma nova forma de gestão que vai reconduzir as práticas gerenciais, promovendo o maior envolvimento do trabalhador, redirecionando as formas de controle sobre o trabalho (ANTUNES, 1999). Esse modelo de gestão induz à ideia de motivação ao invés de coerção, ao trabalho em equipe, à autonomia e à criatividade e, marca de forma acentuada o ideário da participação, criando a ilusão de que os sujeitos têm o poder de deliberar sobre as questões que envolvem o trabalho, as relações sociais e educacionais, sem que percebam as teias alienantes que permeiam estas relações. Nessa perspectiva, o capital e o capitalismo se utilizam da educação como um incremento na obtenção dos seus propósitos.

\section{3 | AS PERSPECTIVAS PARA A EDUCAÇÃO FORMAL EM MEIO ÀS RELAÇÕES TRABALHO E EDUCAÇÃO}

A difusão das concepções que consolidam o contexto, anteriormente destacado, reforçou as iniciativas de promoção dos programas de educação para a competitividade, uma vez que a educação adquiriu uma certa centralidade nos novos "modelos" de produção. Num primeiro momento, chegou a ocorrer certo grau de otimismo diante da possibilidade de resgatar a dívida social de longa data, que não viabilizava, para a maioria da população, o direito à educação (SHIROMA; MORAES; EVANGELISTA, 2002). A universalização do Ensino Básico e uma maior qualificação foram apresentadas como possibilidade de avanços e de resgate da dignidade do trabalhador, com a ampliação da escolaridade.

Desse modo, a escola básica, passou a ser defendida como universal, laica, gratuita e obrigatória a todos, no Brasil, por exemplo, oferta-se formação polivalente visando à qualificação de mão de obra para o mercado. Essa ideia de preparação de mão de obra, obviamente, está voltada muito mais ao campo tecnicista do que propriamente humano. Esses requisitos foram colocados como necessários para o desenvolvimento equitativo e para a inserção dos países latino-americanos na economia globalizada. Essas orientações, emanadas não só de organismos como a Comissão Econômica para a América Latina e o Caribe (CEPAL), mas, também, da Organização das Nações Unidas para a Educação, a Ciência e a Cultura (UNESCO), do Banco Mundial, objeto também da Conferência Mundial da Educação para Todos, realizada em Jontiem (Tailândia, 1990), vinham prescrevendo o urgente aumento de escolaridade como condição sinequa non para a adoção de novas tecnologias, inserção e posicionamento do país no mundo globalizado.

Os documentos estabelecidos por estes organismos passaram a definir a ideia da centralidade da educação em conexão com o novo paradigma produtivo. Eles apresentam a produção e a acumulação do conhecimento como força motriz do desenvolvimento, postulando uma nova "economia da educação" que, embora trabalhe com o conceito de capital humano, se diferencia daquela que dominou nas décadas de 1950 e 1960. As orientações estratégicas da Cepal e de outros organismos mundiais estabeleceram diretrizes para a reforma educacional na América Latina, colocando como eixo central dos seus projetos e financiamentos a prioridade para a Educação Básica. Essas orientações também foram assimiladas pelo governo brasileiro, que, desde mea- 


\section{A RELAÇÃO ENTRE TRABALHO E EDUCAÇÃO | Clarice Zientarski}

meados de 1990, passou a priorizar e financiar projetos de recuperação da Educação Básica em parcerias com empresários e outros organismos não-governamentais.

A ênfase na educação básica passou a buscar dois objetivos:

a) elevar o nível de escolaridade dos trabalhadores, mudança que se impõe tanto para o melhor desempenho profissional, quanto para o desenvolvimento de uma "nova mentalidade", particularmente de atitudes mais receptivas a mudanças;

b) dotar o trabalhador de uma base sólida de educação geral, condição necessária para maior treinabilidade em serviço e para programas de educação continuada, adaptando-os, dessa forma, à flexibilidade e às crescentes mudanças nos processos produtivos (CAMPOS, 1997, p. 46-47).

A educação conforme Saviani (1999) é inerente ao ser humano, pois, originou-se do mesmo processo que deu origem social ao homem. Assim "desde que o homem é homem ele vive em sociedade e se desenvolve pela mediação da educação" (SAVIANI, 1999, p.1). A educação, portanto, é decisiva para a vida dos seres humanos, sendo criada e recriada por eles, na interação com outros seres vivos com os quais se relacionam. Compreendida desta forma, ela estaria servindo como instrumento de emancipação e libertação dos homens como seres históricos dotados de capacidade de transformação. O que se tem constatado, no entanto, é que longe de tornar as pessoas capazes de construírem e reconstituírem a sua própria vida, de transformarem a sua realidade e interagirem na sociedade, a educação tem contribuído com a manutenção das estruturas vigentes em cada contexto histórico.

No Brasil esta realidade pode ser vista desde o processo de colonização, em que não se estabeleceu a relação entre educação e desenvolvimento do povo, priorizando a educação das classes privilegiadas social e, economicamente, deixando a maioria da população excluída de qualquer proposta de escolaridade. Nesta lógica, a educação, especialmente a desenvolvida pela escola formal, foi um dos instrumentos de que lançaram mão os sucessivos grupos que ocuparam o poder, para promover e preservar a dependência, por meio da exclusão, que se efetivou na impossibilidadedo acesso e ou da permanência de grande parte dos brasileiros na escola, ou então por meio de um ensino de submissão, desprovido da preocupação crítica, e com métodos e conteúdos inadequados à formação humana, voltados para os interesses do capital.

Ao atender os interesses do capitalismo internacional e também nacional, no Brasil, aliada à exclusão e à desigualdade social, a educação torna-se um problema social. Associada à economia de mercado e à divisão das classes sociais (FERNANDES, 1994), a educação reproduz, inevitavelmente, a desigualdade social e a pobreza. Dessa forma, as políticas educacionais, sem ter conseguido atacar as forças geradoras básicas que alijam a população das perspectivas de um processo educacional emancipatório, corroboram com o que está posto, isto é, contribuem com o alargamento das desigualdades se ocupando com ações que são patrocinadas e definidas por organismos internacionais como o Banco Mundial, o Fundo Monetário Internacional (FMI), UNESCO, ONU, a OEI, dentre outros.

Entre as prioridades e estratégias do Banco Mundial e dos demais organismos internacionais, destaca-se o fato de que ele "[...] postula menos burocracia estatal na educação e mais flexibilidade local [...]" (LAUGLO, 1997, p. 23). Assim, a imposição de critérios por esses organismos traduz-se em definições para as pautas de discussões sobre a situação das políticas educacionais brasileiras. Ao mesmo tempo, a legislação educacional propõe, através do entendimento em torno da descentralização, a ampliação da autonomia aos Estados e Municípios e às próprias escolas, de modo que aspectos locais do espaço micro sejam relevantes na consecução de objetivos para o ensino.

Nesse contexto, o trabalho desenvolvido nas instituições de ensino, embora sob outros princípi- 


\section{A RELAÇÃO ENTRE TRABALHO E EDUCAÇÃO | Clarice Zientarski}

pios, por conta do toyotismo, ainda apresenta-se fragmentado, descontextualizado e hierarquizado, embora sob a aparência da autonomia pedagógica e administrativa. $O$ trabalho realizado de forma segmentada indica uma lógica de incorporação dos métodos de gerenciamento das empresas capitalistas na gestão do espaço escolar reproduzindo a lógica empresarial. Conforme Chiavenato (2003, p. 82):

[a] função administrativa não se concentra exclusivamente no topo da empresa e nem é privilégio dos diretores, mas é distribuída proporcionalmente entre todos os níveis hierárquicos. À medida que se desce na escala hierárquica, mais aumenta a proporção das outras funções da empresa e à medida que se sobe na escala hierárquica, mais crescem a extensão e o volume das funções administrativas.

Com o modelo toyotista de produção em destaque, conforme assegura João Bernardo (2004, p. 80), cujo modelo resultou da "dupla tomada de consciência dos capitalistas de que era necessário explorar a componente intelectual do trabalho e de [...] fragmentar ou mesmo dispensar os trabalhadores"; na educação formal, nas escolas, a situação é semelhante, professores são contratados, são substituídos, os professores são polivalentes, o ensino desenvolve-se inclusive à distância e os empresários definem os rumos da educação. Consoante expõe Giddens (1990, p. 62), na sociedade capitalista "a autonomia do Estado é condicionada, embora não determinada num sentido forte, pela sua dependência da acumulação do capital, sobre o qual seu controle está longe de ser completo." Peroni (2003) sinaliza que o mercado é que deverá superar as falhas do Estado e, assim, a lógica do mercado deve prevalecer inclusive no Estado e na Escola, para que ele possa ser mais eficiente e produtivo. Ignoram-se neste caso, os professores, os estudantes e demais componentes da comunidade educativa e, acima de tudo, os direitos sociais,compreendidos como "a raiz dos direitos humanos, pois estes somente medram onde a sociedade se faz sujeito histórico capaz de discernir e efetivar seu projeto de desenvolvimento." (DEMO, 1995, p. 3).

É o que pode ser observado nas escolas da rede pública estadual do Ceará, a partir do seu cotidiano, pois, conforme sublinha Lukács (1994, p. 11) "a sociedade só pode ser compreendida em sua totalidade, em sua dinâmica evolutiva, quando se está em condições de entender a vida cotidiana em sua heterogeneidade universal." Com estas premissas busca-se apreender o significado das ações baseadas nas particularidades imediatas, no cotidiano das instituições de ensino.

\section{4 | A PARCERIA PÚBLICO/PRIVADO NO ESTADO DO CEARÁ: a reafirmação das relações entre Trabalho e Educação}

Ao se identificar como se dão as relações entre Trabalho e Educação empiricamente, ou, em suas particularidades cotidianas (LUKÁCS, 1994), constatou-se que as escolas pesquisadas, além de outros programas e ações desenvolvem os Projetos: Jovem do Futuro/Instituto Unibanco (PJF) e Ensino Médio Inovador (EMI)/MEC-ProEMI/JF¹. Tais projetos, e especialmente o PJF, neste estudo, torna-se o foco de pesquisa.

O Jovem de Futuro é um projeto de Gestão Escolar para Resultados da Secretaria de Educação do Ceará (SEDUC) em parceria com o Instituto Unibanco que oferece às escolas participantes apoio técnico e financeiro para, em um período de 3 anos (duração do Ensino Médio)

\footnotetext{
${ }^{1}$ O Programa Ensino Médio Inovador (ProEMI), instituído pela Portaria $n^{\circ}$ 971, de 09 de outubro de 2009, foi criado para provocar o debate sobre o Ensino Médio junto aos Sistemas de Ensino Estaduais e do Distrito Federal (BRASIL, 2009).
} 


\section{A RELAÇÃO ENTRE TRABALHO E EDUCAÇÃO | Clarice Zientarski}

melhorar substancialmente seu desempenho. Para atender aos objetivos do projeto, as escolas recebem capacitação e assessoria técnica para planejar, executar, acompanhar e avaliar uma proposta de melhoria de seus resultados e $\mathrm{R} \$ 100,00$ (cem reais) por aluno/ano para financiar as ações estratégicas previstas neste plano. A ideia básica defendida no referido projeto é a de que não existe organização, sobretudo instituição voltada para o interesse público sem qualificação técnica de gestão. O projeto deve ser realizado em consonância com as determinações do Instituto, tendo, inclusive, um modelo de elaboração do plano, e nas planilhas pré-estabelecidas as escolas participantes lançam as respostas conforme o solicitado.

O Programa Jovem de Futuro em cada escola possui um Grupo Gestor composto por:

a) Diretor da Escola - membro nato;

b) Coordenador do projeto na escola;

c) Representante dos professores;

d) Representante de alunos;

e) Representante de pais. (CEARÁ, 2014).

Os princípios orientam para um trabalho com foco nos resultados positivos de ensino e aprendizagem. Neste sentido, apresenta aos gestores escolares estratégias e instrumentos que tornem o trabalho escolar eficiente, criativo e produtivo, ou seja, assim como no mercado de trabalho, estas são exigências semelhantes, caracterizando a lógica produtivista do modo de produção capitalista no âmbito das escolas.

Nas escolas da rede pública estadual do Ceará, a preocupação com a formação dos estudantes tem sido para o mercado de trabalho, seguindo a lógica do capital, e não para o trabalho como categoria genérica do ser, sendo que estas concepções se fazem presente nos projetos político pedagógicos, nos encontros de formação de professores, nos projetos e nas diretrizes apontadas pela gestão. Nesse contexto, os princípios da meritocracia se fazem presentes na premiação de estudantes, resultado das ações de um Estado Avaliador, como pode ser visto no final do ano de 2014, quando divulgada a lista dos melhores alunos, sendo esta premiação respaldada pelas Leis $n^{\circ} 15.572$, de 07 de abril de 2014, e n 15.702, de 20 de novembro de 2014. A Secretaria da Educação premiou os estudantes com base nos resultados do Exame Nacional do Ensino Médio (ENEM) e Sistema Permanente de Avaliação da Educação Básica do Ceará (SPAECE), ambos de 2013.

Os dados obtidos indicam que as escolas têm como foco principal a preparação para o mercado de trabalho, o ingresso na universidade, a meritocracia e apontam as parcerias existentes, conforme salienta o Coordenador Pedagógico da Escola $X^{2}$, Professor Rubens:

A escola trabalha com projetos, visando principalmente a preparação de cidadãos para o mundo do trabalho e conclusão do ensino médio. Este é o caso do Projeto Jovem de Futuro que é uma ação do governo federal em parceria com o Instituto Unibanco. Este conta com investimentos na escola em ações voltadas para a permanência, bom desempenho e conclusão do ensino médio por parte dos alunos, através de investimentos em oficinas, compra de equipamentos, locação de ônibus para realizar as aulas de campo visando, inclusive melhorar a qualidade da educação. O projeto, portanto, visa o mercado de trabalho e fazer a escola buscar sempre ser a melhor. (grifo nosso).

\footnotetext{
${ }^{2}$ As escolas estão identificadas pelas letras $\mathrm{J}, \mathrm{K}, \mathrm{L}, \mathrm{M}, \mathrm{N}, \mathrm{O}, \mathrm{X}, \mathrm{Y}, \mathrm{Z}, \mathrm{W}$ e a pedido das direções, os documentos das referidas escolas foram xerocopiados e encontram-se no banco de dados do Departamento de Fundamentos da Educação da Universidade Federal do Ceará (UFC). As entrevistas, identificadas, foram gravadas e transcritas e estão à disposição no mesmo local. Os professores são identificados por pseudônimos para preservar o anonimato. Na realização das entrevistas, durante o ano de 2014, contou-se com a participação de estudantes de graduação da UFC, do curso de História, além dos componentes do Grupo de Estudos (GEPEUFC).
} 


\section{A RELAÇÃO ENTRE TRABALHO E EDUCAÇÃO | Clarice Zientarski}

Conforme se observa na fala do professor o projeto tem o objetivo "inclusive de melhorar a qualidade da educação", como se este não devesse ser um dos principais motivadores de projetos e ações, ao contrário, aparece como algo estanque que distancia e separa qualidade da preparação para o mundo do trabalho e ingresso na universidade. A formação humana dos estudantes, a formação para o trabalho concreto, ou para a emancipação, em nenhum momento foi destacada na fala deste professor ao se referir aos projetos desenvolvidos na escola.

Ao ser perguntado sobre como foi pensado o projeto Jovem de Futuro na escola, o Professor Rubens respondeu:

Nós participamos de uma reunião de apresentação do projeto. Ele é um programa de governo federal ligado ao ProEMI como já falei, e atrela verba do PDDE Escola à escola que hoje é chamado de PDE Interativo. Então o dinheiro do PDE a gente justifica por meio de um plano de ação onde tenha várias ações vinculadas ao aluno e todas as ações tem que estar voltadas ao combate à evasão combate à reprovação e qualificação do professor. $\mathrm{Na}$ escola temos ações ligadas às oficinas esportivas, de cinema, de redação, de inglês, de espanhol, de cabeleireiro, de maquiagens e oficinas esportivas de handebol, karatê, xadrez e voleibol, todas vinculadas aos projetos de preparação para o ingresso na universidade, por exemplo, o pré ENEM, e os projetos para inserção no mercado de trabalho, pois, muitos que concluem o ensino médio não continuam seus estudos no Ceará.

No que diz respeito ao programa Programa Ensino Médio Inovador (ProEMI), citado pelo professor, ele é mais um dos tantos programas do Governo Federal, e não caracterizam ações efetivas de Estado ${ }^{3}$, mas de governo, e conforme destacado anteriormente, integra as ações do Plano de Desenvolvimento da Educação (PDE), como estratégia do Governo Federal para induzir a reestruturação dos currículos do Ensino Médio, compreendendo que as ações propostas vão sendo incorporadas ao currículo das escolas, ampliando o tempo na escola e a diversidade de práticas pedagógicas, atendendo às necessidades e expectativas dos estudantes do Ensino Médio.

O professor tem razão em sua afirmação sobre a preocupação com a continuidade de estudos no Ceará e conclusão do Ensino Médio, pois, os dados do censo escolar indicam que iniciaram o Ensino Médio no Ceará em 2008, 153.169 estudantes, em 2009, 118.721 frequentavam o $2^{\circ}$ ano e, em 2010, 96.559 estavam matriculados no $3^{\circ}$ ano do Ensino Médio ${ }^{4}$, portanto, mais de cinquenta e seis mil estudantes, evadiram apenas neste período de tempo.

No que diz respeito ao fato da escola aderir ao projeto, o professor remete ao MEC e ao Instituto Unibanco sem mencionar a SEDUC, entretanto, partiu da SEDUC/CE o acordo com o Instituto Unibanco para que o projeto fosse implantado no Ceará. O projeto é uma parceria entre a Secretaria de Educação do Ceará, o Instituto Unibanco e MEC.

A fala do professor e os dados levantados a respeito do projeto originam a preocupação em relação ao currículo das escolas, pois se as ações vão sendo incorporadas ao longo do processo, efetivamente ele não foi contemplado no momento em a escola produziu seu Projeto Político Pedagógico (PPP).

\footnotetext{
${ }^{3}$ Considera-se que políticas de governo são aquelas que o Executivo decide num processo elementar de formulação e implementação de determinadas medidas e programas, visando responder às demandas da agenda política interna, ainda que envolvam escolhas complexas. Já as políticas de Estado são aquelas que envolvem mais de uma agência do Estado, passando em geral pelo Parlamento ou por instâncias diversas de discussão, resultando em mudanças de outras normas ou disposições preexistentes, com incidência em setores mais amplos da sociedade (OLIVEIRA, 2011, p. 329).
}

${ }^{4}$ Dados do censo escolar de 2011 (BRASIL, 2011). 


\section{A RELAÇÃO ENTRE TRABALHO E EDUCAÇÃO | Clarice Zientarski}

Em relação à forma como o trabalho é realizado nas escolas para o desenvolvimento dos projetos, todos os entrevistados afirmaram que é desenvolvido em forma de oficinas ou atividades extraclasse, ou seja, de maneira fragmentada. Além disso, são contratadas pessoas para a realização destas ações, não se trata de plano que faça parte do Projeto Político Pedagógico da escola, ou seja: (pretende ser incorporado aos poucos), nem tampouco se integra às aulas de uma maneira geral, pelo contrário, o documento orientador indica que o PJF "alinha o Projeto Político Pedagógico (PPP) da escola, compreendendo o Jovem de Futuro e demais projetos num único plano de ação" (INSTITUTO UNIBANCO, 2007). Estabelece-se nesta lógica um processo inverso: ao invés de partir da elaboração do PPP, que precisa ser um documento construído coletivamente (BRASIL, 1996), definirem-se as diretrizes e os objetivos para a escola e a comunidade educativa em seu conjunto, o PPP é que deve se alinhar ao PJF. Perde com isso a comunidade a sua autonomia e o direito de definir as políticas educacionais em nível micro, na escola.

A Professora Sandra, Escola M, explica em relação à construção do PPP e ao projeto que:

O projeto político pedagógico da nossa escola foi elaborado há três anos. Todos os anos nós temos a função de alterar, de verificar o que foi feito, os resultados, os indicadores, entretanto, tivemos mudança de direção e por isso, ele ainda não foi alterado, então, nele não consta nada sobre o projeto, nem sobre a formação continuada.

$\mathrm{Na}$ escola da professora Sandra o PPP precisa ser alterado em razão do PJF e de outras ações que foram sendo implantadas na escola. Compreende-se que as ações devem sim acontecer, pois, a escola é movimento e está em movimento, porém, algo que provoca mudanças no currículo, na definição de objetivos e direcionamento da escola precisa sim fazer e ter parte no PPP. Ainda, sobre o PPP é importante salientar que durante a pesquisa, nas visitas às escolas, poucas são as que no momento inicial dos contatos apresentavam o PPP, também quando os estudantes foram perguntados a respeito do documento, muitos diziam não saber de sua existência e não participaram de sua elaboração. A resistência em divulgar o documento, colocá-lo à disposição da comunidade e principalmente de elaborá-lo coletivamente, provocam questionamento quanto aos princípios da gestão democrática da escola pública.

A Gestão Escola para Resultados (GEpR), proposta pelo Instituto Unibanco (2014) determina que deve acontecer na escola: a Integração de processos e ferramentas; Mobilização e articulação de recursos humanos, técnicos, materiais e financeiros; Divisão de responsabilidades; Sistema de informações (monitoramento, controle e avaliação); Sistemas de incentivos e sanções (avaliação); Comunicação e marketing interno e externo (mobilização); Mecanismos de capacitação (comunidades de aprendizagem).

Conforme salienta o professor Cristian, coordenador pedagógico da Escola Z, a formação do pessoal encarregado de desenvolver o projeto, dispõe que devem participar dos encontros de formação: 03 (três) pessoas por escola, sendo elas o diretor, o coordenador do PJF na unidade escolar e mais um representante dos membros do grupo/comitê gestor. Neste caso, pela afirmação do professor, não se trata de proposta de formação continuada, articulada ao PPP, que envolveria o coletivo dos professores, o que poderia contribuir sim com a formação de professores. Trata-se, de uma formação descontextualizada orquestrada e regida pelo instituto, aceita pelo Estado, que os professores acabam "aceitando sem muitas discussões" como assegura a Professora Raquel da Escola N. A professora afirma ainda que "aqui no [...], nem os pais nem nós os professores temos condições de participar de reuniões ou de encontros de formação fora dos horários de aula".

Ainda no que se relaciona à formação por parte do Instituto, no segundo semestre de 2014, o instituto abriu inscrições para a formação à distância para os professores sublinhando que o objetivo dos cursos a distância é: 


\title{
A RELAÇÃO ENTRE TRABALHO E EDUCAÇÃO | Clarice Zientarski
}

\begin{abstract}
[...] disseminar e favorecer a implementação das Metodologias Jovem de Futuro nas escolas públicas parceiras, por meio de cursos promovidos no Ambiente Virtual de Aprendizagem (AVA) do IU, buscando aproximar as instituições de ensino integrantes do projeto e contribuir para que a aplicação das Metodologias seja efetiva. (INSTITUTO UNIBANCO, 2014).
\end{abstract}

Esta forma de proceder em relação à formação, bem como na maneira de realizar o trabalho na escola, quando se submete à instituição educativa aos programas externos, com trabalho fragmentado, descompassado e estranhado (MARX, 2011), provoca o isolamento, a perda da visão global da própria escola, e reafirma a lógica das fábricas, nas quais cada um executa o seu trabalho ainda baseados na divisão do trabalho, no gerenciamento empresarial do modelo taylorista/ fordista, embora sob a égide de uma liberdade, de um trabalho flexível e polivalente sustentado pelo toyotismo, que supostamente superaria a alienação (o estranhamento) do trabalho.

Nesse sentido, reafirma-se a relação estreita entre trabalho e educação, cujas implicâncias são vislumbradas na formação dos estudantes e no tipo de trabalho que é realizado nas escolas, que culmina nas formações que recebem os profissionais das escolas, tendo em vista que:

[...] periodicamente os gestores escolares e outros dois representantes da comunidade escolar, além de técnicos das secretarias de educação, participam de formações presenciais sobre o conceito de Gestão Escolar para Resultados. Nesses encontros, debatem questões pertinentes ao cotidiano na escola e uma gestão orientada para resultados de aprendizagem. (INSTITUTO UNIBANCO, 2014).

Assim, confirma-se o que defendem Shiroma, Moraes e Evangelista (2002, p. 72) quando asseguram em relação ao Banco Mundial que "um banco define as prioridades e estratégias para a educação". E, neste caso, fazendo uma analogia em relação à afirmação das autoras, pode-se inferir que cabe ao Instituto Unibanco ou outras instituições parceiras definirem as primazias educacionais no Ensino Médio, no Ceará.

A coordenadora pedagógica da Escola W, que faz parte do núcleo gestor do programa PJF, durante o dia e é a responsável pela coordenação do projeto Professor Diretor de Turma, destaca que uma das dificuldades em relação ao trabalho da escola é a evasão e o abandono, especialmente dos alunos do turno noturno. Salienta ainda a professora, que assim como os estudantes evadem e ocorrem muitas trocas, pois alunos do diurno passam para o noturno por "ingressar no mercado de trabalho", também entre os professores e funcionários existe uma grande rotatividade, tendo em vista que muitos são contratados temporariamente e estes contratos algumas vezes são rompidos durante o ano letivo. Segundo a Professora Michele, Escola L, a falta de continuidade no trabalho faz com que: "Uma professora inicia com a turma, se afasta, outra pega, algumas vezes entra mais uma, quer dizer, se rompe e se fragmenta cada vez mais, mas a gente fica feliz quando tem professor". A professora assegura ainda: "quando vem alguma ação ou projeto de fora a gente aceita, porque nos parece ser uma possibilidade a mais diante da precariedade que temos na escola".

\footnotetext{
${ }^{5}$ O Projeto Professor Diretor de Turma teve sua origem, aqui no Brasil, por ocasião do XVIII Encontro da Associação Nacional de Política e Administração da Educação (ANPAE) - Seção do Ceará, no ano de 2007, quando foi apresentada a experiência das escolas públicas portuguesas. Baseados nessa apresentação, gestores educacionais dos municípios de Eusébio, Madalena e Canindé iniciaram um projeto piloto em três escolas. Considerado pela SEDUC como um sucesso, ocorreu a expansão para as escolas de ensino regular da rede pública estadual (CEARÁ, 2007). No projeto, cada turma tem um professor responsável que procura conhecer detalhes da vida do aluno e de sua família.
} 


\section{A RELAÇÃO ENTRE TRABALHO E EDUCAÇÃO | Clarice Zientarski}

Nesse enfoque, percebem-se as dificuldades e limitações da escola pública, pois os anseios para que "alguma coisa nova que é trazida pelos parceiros da escola para nós é fundamental, pois, temos poucos recursos, além disso, quando surge alguma complementação para o nosso salário a gente abraça mesmo." (Francisca, Escola K). A Professora Francisca revela, por um lado, em poucas palavras o abandono da escola pública e reafirma o que foi discutido no início deste trabalho quando se apresentou o afastamento do Estado e a ocupação deste espaço por instituições do terceiro setor. $O$ depoimento da professora por outro lado, apresenta a importância de formar uma "nova mentalidade" (CAMPOS, 1997, p. 46-47), isto mostra que apesar dos limites dos programas, eles contribuem com a formação dos estudantes e professores. Evidencia, ainda, a fragmentação que deixa clara a visão de trabalho desenvolvido nestes espaços, nesse espectro ainda "taylorizado" de trabalho, em que a educação e a organização pedagógica se colocam desta forma, passando a ser regidas pelos princípios da divisão do trabalho.

As ações segmentadas indicam uma lógica de incorporação dos métodos de gerenciamento das empresas capitalistas na gestão do espaço, em que os professores trabalham, como se verifica na expressão da Professora Michele, Escola L: "aqui na escola cada um procura fazer seu trabalho, nós que somos da equipe gestora encontramos muita dificuldade por causa disso". Desenvolve-se nesta lógica, um trabalho fragmentado, em que se enfatiza a repetição mecânica das tarefas padronizadas, com a expectativa de que, por meio desta forma de trabalho se atinjam os padrões educacionais colocados como parâmetros de medidas por instituições, como os bancos, por exemplo.

O Coordenador Pedagógico da Escola K, professor Robson afirma que as atividades que envolvem os projetos são desenvolvidas em turno extra, ficando marcadas como intenções principais do ensino na escola:

[...] a questão da cidadania, a importância do ensino para as avaliações externas como vestibulares, avaliações estaduais, o entendimento para os estudantes que o processo educativo não se encerra na escola e principalmente a possibilidade de preparação para o mercado de trabalho, tendo em vista que as empresas querem pessoas qualificadas (grifo nosso).

O que se evidencia neste aspecto, é que a educação, mesmo sob o olhar dos professores, tem o compromisso com o capital de preparar para o mercado de trabalho e passou a fazer parte do mundo empresarial. A professora Raquel vai além e salienta que: mesmo desenvolvendo este tipo de projetos a escola acaba "não preparando adequadamente para o mercado" e, de uma maneira geral, "os empresários reclamam sobre a formação". A educação, neste caso, deixa de ser parte do campo social e político para ingressar no mercado e funcionar de acordo com a sua semelhança e, assim, "fica atrelada à preparação para o trabalho, submetida aos "imperativos do mercado ou às necessidades da livre iniciativa" (MARRACH, 1996, p. 42-56). Isto faz com que a educação atenda às necessidades e interesses do mercado de trabalho e à lógica empresarial.

As concepções emanadas do mundo empresarial criam nos professores e estudantes, a ilusão de que eles, ao aderirem aos projetos e programas definidos pelo capital estão adentrando em: "acreditamos que a escola vai atingir um patamar de qualidade, se colocando no ranking das melhores da capital" (Professor Ronaldo Gestor da Escola Y), como se isto implicasse em qualidade de vida e ou emancipação. Nesse sentido, o padrão de qualidade advindo dos novos modelos de gestão, transmitido pelo discurso da excelência, remete ao mundo do trabalho preconizado pelo controle que é exercido sobre os trabalhadores e no caso das escolas sobre os professores e estudantes. 


\section{A RELAÇÃO ENTRE TRABALHO E EDUCAÇÃO | Clarice Zientarski}

Ainda, no que se refere às avaliações e controle, tendo em vista o modelo de Estado centrado na avaliação, assim como os modelos de gestão das empresas articulam as políticas de flexibilização e envolvimento dos trabalhadores, gerando relações cada vez mais competitivas, nas escolas em nome da qualidade, criam-se instrumentos de controle e geram-se a competição desenfreada entre as escolas, entre estudantes, controlam-se o trabalho e inclusive a assiduidade dos professores, como se pode perceber no PJF. O Projeto tem por objetivo em relação aos alunos, que desenvolvam competências em Língua Portuguesa e Matemática e tenham alto índice de frequência; para os professores alto índice de frequência e práticas pedagógicas melhoradas; e, para a gestão: efetividade do grupo gestor, diversidade de parcerias e infraestrutura melhorada, quer dizer, o controle está em todos os setores, sem contar nas demais avaliações externas às quais as escolas estão submetidas.

Enfim, em uma "sociedade do capital, a educação e o trabalho se subordinam a essa dinâmica, da mesma forma que em uma sociedade em que se universalize o trabalho". Nesse caso, uma "sociedade em que todos se tornem trabalhadores, somente ai se universalizará a educação" (MÉZSÁROS, 2010, p. 17). Assim, em consonância com Mészáros (2002, p. 116), compreende-se que a educação poderia se apresentar como um complexo importante para o entendimento e superação dos problemas sociais, porém, encontra-se subordinada à base de acumulação do capital "a hipostasiada instituição da 'paz perpétua' sobre a base material do microcosmos internamente fragmentados do capital não passa de doce ilusão." Neste prisma, conforme Lukács (1994, p. 60) "é preciso assumir um ponto de vista crítico" em relação a estas questões que envolvem a educação, o trabalho e o capital. A saída, portanto, vislumbrar-se-á com a destruição do modo capitalista de produção, pois, o capital é um complexo tão alienante, tão poderoso, que a humanidade pode destruir: controlar, jamais (MÉSZÁROS, 2010; PANIAGO, 2007).

\section{5 | CONSIDERAÇÕES FINAIS}

A conjuntura das políticas educacionais no Brasil demonstra sua centralidade na hegemonia da ideologia neoliberal sobre a sociedade, como reflexo do forte avanço do capital sobre a organização dos trabalhadores, especialmente a partir da década de 90. (ANDRIOLI,2002). A intervenção de mecanismos internacionais como o $\mathrm{FMl}$ e o Banco Mundial, aliada à subserviência do governo brasileiro à economia mundial, repercute de maneira decisiva sobre a educação.

A estratégia defendida é a de colocar a educação como prioridade, apresentando-a como alternativa de "ascensão social" e de "democratização das oportunidades". Efetivamente, no entanto, no âmbito educacional, difundido pelo capital é a racionalidade empresarial. Os valores que ela apregoa são a eficiência como caminho para a competitividade e a produtividade e o lucro como recompensa e fins a serem auferidos; sendo a educação um bem de consumo e fonte de lucro, ela torna-se acessível somente a uma pequena margem da sociedade.

Ao invés da apregoada inclusão, a tendência é a progressiva seletividade e elitização do conhecimento. As conseqüências deste modelo podem ser observadas no quadro educacional brasileiro e, neste estudo, o Ceará em especial, em que se constata, por meio dos dados divulgados pelos próprios órgãos que tem definido as políticas sociais e educacionais, que a grande maioria da sociedade torna-se vítima da exclusão, do analfabetismo, do desemprego, da miséria e da violência. Vivencia-se, neste contexto, as contradições da atual organização social e o complexo educacional é inundado por medidas imediatistas, muitas vezes descartáveis que servem aos interesses de dominação do modo de produção em curso.

Os dados obtidos na pesquisa evidenciam que as escolas têm como preocupação a formação para o mercado de trabalho, ingresso na universidade, no entanto, inseridas na lógica da merito- 


\section{A RELAÇÃO ENTRE TRABALHO E EDUCAÇÃO | Clarice Zientarski}

cracia. Contam como aliados a própria situação de abandono ao qual a educação tem sido submetida ao longo dos anos, com muitos professores e ainda com estudantes que incorporam esta lógica.

A partir dos objetivos que estes grupos têm e contando com a aceitação e incorporação de seu discurso, que se apresentam como um estímulo às ações e projetos que serão lançados para as escolas, as instituições internacionais, os institutos, fundações e o próprio Estado, se utilizam destes dados para culpabilizar os professores e as escolas como sendo incompetentes para desenvolver um processo educativo de qualidade. Nesta lógica cabe aos bancos e empresariado em geral, ensinar aos professores como se desenvolve "um ensino de qualidade", como se deve gestar a escola e como se prepara os estudantes para o mercado de trabalho, pois eles serão as forças produtivas que estarão sendo vendidas aos capitalistas.

Para incorporar estas práticas, a partir de um método de avaliação, as instituições de ensino identificam suas carências e necessidades em cada aspecto da vida escolar (notas médias, perfil dos professores, rotinas administrativas, instalações físicas) e definem suas próprias matrizes de planejamento. Ignoram-se neste caso, os professores, os estudantes, a comunidade educativa em seu conjunto e acima de tudo, os direitos sociais compreendidos como a essência dos direitos humanos, como sublinha Pedro Demo (1995). O processo de construção da gestão democrática é prejudicado, porque são outros órgãos que definem o andamento do trabalho escolar, burocratizam o trabalho das escolas, tornando os professores e gestores meros burocratas, o que contradiz a LDB em seus artigos 14 e 15 que tratam sobre a gestão democrática da escola pública.

Constatou-se, portanto, que as parcerias com os institutos privados e outros órgãos externos às escolas reforçam e consolidam a relação entre trabalho e educação, sob a ótica do capital, e, neste prisma, retira direitos, precarizam, fragilizam e fragmentam o trabalho dos professores e demais educadores da escola, por meio de ações que negam as bases democráticas, inserindo as escolas na lógica do mercado e da meritocracia. 


\section{A RELAÇÃO ENTRE TRABALHO E EDUCAÇÃO | Clarice Zientarski}

\section{Referências}

ANDRIOLI, Antônio. As políticas educacionais no contexto do neoliberalismo. Revista Espaço Acadêmico.

Ano 2. N¹3. Junho de 2002. Mensal.ISSN.1519.6186. Disponivel em: http://www.espacoacademico.com. br/013/13andrioli.htm. Acesso dia 24/03/2015.

ANTUNES, R. A desertificação neoliberal no Brasil (Collor, FHC e Lula). Campinas: Autores Associados, 2004.

Os sentidos do trabalho: ensaio sobre a afirmação e a negação do trabalho. 2. ed. São Paulo: Boitempo, 1999.

BERNARDO, J. Democracia totalitária: teoria e prática da empresa soberana. São Paulo: Cortez, 2004.

BRASIL. Constituição (1988). Constituição da República Federativa do Brasil. Brasília, DF: Senado Federal, 1988. Disponível em: <http://www.planalto.gov.br/ccivil_03/constituicao/constituicaocompilado.htm>. Acesso em: 25 out. 2014.

Lei $n^{\circ}$ 9.394, de 20 de dezembro de 1996.

Estabelece as diretrizes e bases da educação nacional. Diário Oficial da União, Brasília, DF, 23 dez. 1996 Disponível em: <http://www.planalto.gov.br/ccivil_03/ leis/I9394.htm>. 25 out. 2014.

Ministério da Educação. Instituto Nacional de Estudos e Pesquisas Educacionais Anísio Teixeira. Censo escolar 2011. Brasília, DF, 2011. Disponível em: <http://portal.inep.gov.br/basica-censo>. Acesso em: 13 dez. 2014.

Portaria $n^{\circ} 971$, de 9 de outubro de 2009. Institui o Programa Ensino Médio Inovador. Diário Oficial da União, Brasília, DF, 13 out. 2009.

CAMPOS, R. de F. A nova pedagogia fabril: tecendo a educação do trabalhador. 1997. 228 f. Dissertação (Mestrado em Educação) - Centro de Ciência da Educação, Universidade Federal de Santa Catarina, Florianópolis, 1997.

CEARÁ. Secretaria da Educação. Projeto jovem de futuro. Fortaleza, 2011. Disponível em: <http://portal.seduc.ce.gov.br/index.php?option=com_content\&view=article\&id=3176: projeto-jovem-de-futuro\& catid=87: :esenvolvimento-da-escola\&ltemid=220 . Acesso em: 13 dez. 2014.

Projeto professor diretor de turma. Fortaleza, 2007. Disponível em: <http://portal.seduc.ce.gov.br/ index.php/87-pagina-inicial-servicos/desenvolvimento-da-escola/3257-diretor-de-turma>. Acesso em: 13 dez. 2014.
Seduc divulga relação de alunos premiados com base no Enem e Spaece 2013. Fortaleza, 2014. Disponível em: <http://www.seduc.ce.gov.br/index. php/noticias/194-noticias-2014/8856-seduc-divulgarelacao-de-alunos-premiados-com-base-no-enem-espaece-2013>. Acesso em: 13 dez. 2014.

CHESNAIS, F. A mundialização do capital. São Paulo: Xamã, 1996.

CHIAVENATO, I. Introdução geral da administração. 7. ed. Rio de Janeiro: Elsevier, 2003.

CORIAT, B. Pensar pelo avesso: o modelo japonês de organização do trabalho. Rio de Janeiro: Ed. UFJ/Revan, 1994.

DEMO, P. Cidadania tutelada e cidadania assistida. Campinas: Autores Associados, 1995. 171 p.

FERNANDES, R. C. Privado porém público: o terceiro setor na América Latina. 2. ed. Rio de Janeiro: Dumará, 1994.

GIDDENS, A. As consequências da modernidade. São Paulo: Ed. UNESP, 1990.

INSTITUTO UNIBANCO. Jovem de futuro: como funciona. [200-]. Disponível em: <http://www.institutounibanco.org.br/jovem-de-futuro/como-funciona>. Acesso em: 14 jul. 2014.

. Revista Gestão escolar para resultados: planejamento e execução, n. 2. São Paulo, 2007.

. Curso sobre metodologias. São Paulo, 2014. Disponível em: <http://www.institutounibanco. org.br/noticias/instituto-unibanco-abre-inscricoes-para-40-mil-vagas-em-cursos-distancia-sobre-metodologias>. Acesso em: 13 dez. 2014.

LAUGLO, J. Crítica às prioridades e estratégias do Banco Mundial para a educação. Cadernos de Pesquisa, São Paulo, n. 100, p. 11-36, mar. 1997.

LUKÁCS, G. As bases ontológicas do pensamento e da atividade do homem. In: Temas de ciências humanas 4. São Paulo: Livraria Ciências Humanas, 1978.

. A fisionomia intelectual dos personagens artísticos. In: LUKÁCS, G. Marxismo e teoria da literatura. Rio de Janeiro: Civilização Brasileira, 1994.

MARRACH, S.A. Neoliberalismo e educação. In: SILVA JR, C.A. da. Infância, educação e neoliberalismo. São Paulo: [s.n.], 1996. 


\section{A RELAÇÃO ENTRE TRABALHO E EDUCAÇÃO | Clarice Zientarski}

MARX, K. O capital 1. São Paulo: Civilização Brasileira, 2011. v. 1.

MARX, K.; ENGELS, F. A ideologia alemã. Tradução e notas de Marcelo Backes. Rio de Janeiro: Civilização Brasileira, 2007.

MÉSZÁROS, I. O poder da ideologia. Tradução Paulo Cezar Castanheira. São Paulo: Boitempo, 2010.

Para além do capital. Tradução Paulo Cezar Castanheira e Sérgio Lessa. São Paulo: Boitempo, 2002.

OLIVEIRA, Dalila Andrade. Das políticas de governo à política de Estado: reflexões sobre a atual agenda educacional brasileira. Educação e Sociedade, Campinas, v. 32, n. 115, p. 323-337, abr./jun. 2011. Disponível em: <http://www.scielo.br/scielo.php?script=sci_arttext\&pid=S0101-73302011000200005\&lng=pt\&nrm=iso\&tl$\mathrm{ng}=\mathrm{pt}>$. Acesso em: 14 jul. 2014.

OLIVEIRA, F. de. A armadilha neoliberal e as perspectivas da educação. Boletim ANPED, Belo Horizonte, v. 12, n. 1/2, p. 7-14, out. 1990. Disponível em: <file:///C:/ Users/usuario/Downloads/Boletim\%20 Anped\%20-\%20 v.12\%20n.1-2\%20jan.-\%20dez.1990.pdf>. Acesso em: 13 dez. 2014.

OLIVEIRA, J. F.; LIBÂNEO, J. C. A educação escolar: sociedade contemporânea. Revista Fragmentos de Cultura, Goiânia, v. 8, n. 3, p. 597-612, 1998.
PANIAGO, C. Mészáros e a incontrolabilidade do capital. Maceió: EDUFAL, 2007.

PERONI, V. M. V. Conexões entre o público e o privado no financiamento e gestão da escola pública. ECCOS: Revista Científica, São Paulo, v. 8, p. 111-132, jan./jun. 2006.

Política educacional e o papel do Estado no Brasil dos anos 90. São Paulo: Xamã, 2003.

PERONI, V.M.V.; OLIVEIRA, R.T.C. de; FERNANDES, M.D.E. Estado e terceiro setor: as novas regulações entre o público e o privado na gestão da educação básica brasileira. Educ. Soc., Campinas, v. 30, n. 108, p. 761-778, out. 2009. Disponível em: <http://www. cedes.unicamp.br>. Acesso em: 13 dez. 2014.

SAVIANI, D. A nova lei da educação: trajetória, limites e perspectivas. 5. ed. Campinas: Autores Associados, 1999.

SHIROMA, E.O.; MORAES, M.C.M. de; EVANGELISTA, O. Política educacional. Rio de Janeiro: DP\&A, 2002. 140 p. 